\title{
Daniel Ortega Martínez, el médico "proletario"
}

\author{
Manuel Almisas Albéndiz \\ Licenciado en Medicina por la Universidad de Cádiz. Profesor Jubilado de Enseñanza \\ Secundaria
}

RESUMEN: El médico Daniel Ortega Martínez (1898-1941), formado en la Facultad de Medicina de Cádiz, ha sido recientemente nombrado «Hijo Adoptivo a título póstumo» por la Corporación municipal de El Puerto de Santa María. Este artículo analiza algunos aspectos de su vida que tiene que ver con dicho nombramiento, y que pone de relieve que era mucho más que un médico con notas brillantes.

Palabras clave: Médico comunista, Segunda República, Homenaje.

\section{Daniel Ortega Martínez, the "proletarian" doctor}

ABSTRACT: The doctor Daniel Ortega Martínez (1898-1941), born in Fuentecén (Burgos) and graduated from the Cádiz Faculty of Medicine, was recently named "Adoptive Son" by the Municipal Corporation of El Puerto de Santa María (Cádiz, Andalucía). This article analyzes some aspects of his life related with this appointment that highlights that he was much more than a doctor with excellent qualifications.

Keywords: Communist doctor, Second Republic, Homage.

El pasado 14 de septiembre tuvo lugar en el Salón del Auditorio Municipal de El Puerto de Santa María el Pleno Solemne donde se nombraba «Hijo adoptivo a título póstumo» de dicho municipio al médico, nacido en Fuentecén (Burgos), don Daniel Ortega Martínez. Expliquemos un poco el contexto de tal distinción, donde el Archivo histórico de la Universidad de Cádiz tuvo su cuota de protagonismo. 
Imagen 1. Marisa y Juan, dos nietos de Daniel Ortega recogen la distinción de manos del alcalde del Puerto de Santa María, David de la Encina, a la derecha de la fotografía.

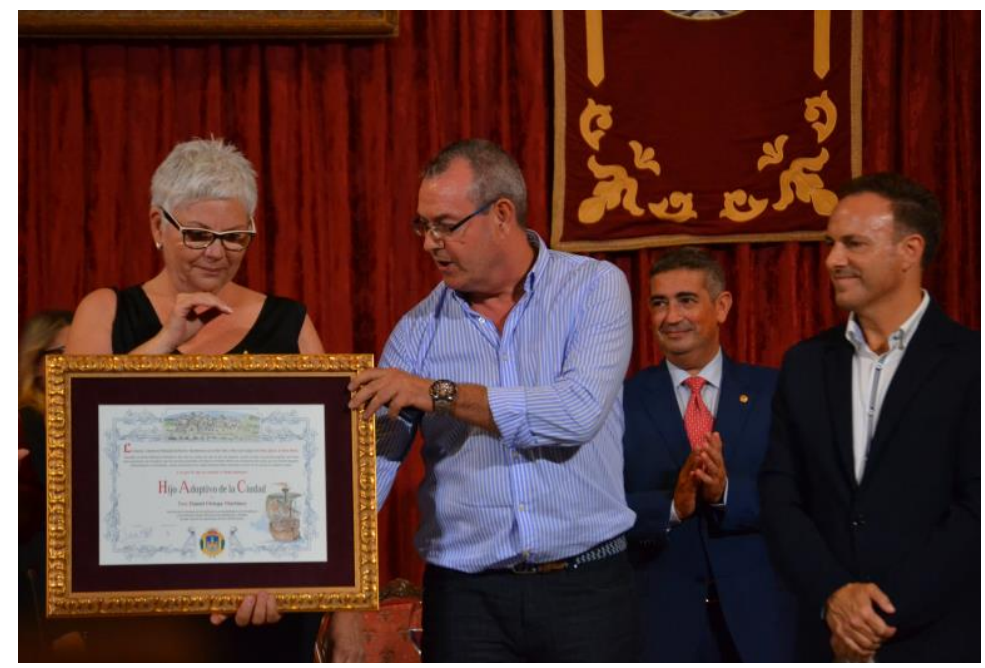

Fuente: Foto de Emilio Rodríguez Posada.

El 18 de enero de 1927 en la sección de noticias de sociedad «Almanaque social» de $E l$ Diario de Cádiz, aparecía publicada esta nota:

«NUEVO MÉDICO: El aplicado joven don Daniel Ortega Martínez, que acaba de licenciarse en Medicina y Cirugía con brillantes notas, se ha establecido en la vecina población de El Puerto de Santa María. Nuestra enhorabuena al nuevo médico y le deseamos muchos éxitos en su carrera».

Estas líneas solo podían provenir de su padre, el conocido maestro afincado en Cádiz Anastasio Juan Ortega Gándara, quien, orgulloso de su hijo mayor, daba a conocer a la sociedad gaditana la noticia del nuevo médico. Y no sería «amor de padre» el hecho de anunciar que Daniel se había licenciado con «brillantes notas». El expediente de su paso por la Facultad de Medicina de Cádiz, presente en el Archivo de la Universidad de Cádiz, no deja lugar a dudas sobre la exactitud de la noticia.

En la primavera de 1924, Daniel Ortega se matriculó en la Facultad de Medicina y presentaba el título de Bachillerato que había concluido en el Instituto «Cardenal Cisneros» de Madrid, donde había estado antes de regresar a Cádiz. Con dicho título convalidó el Curso Preparatorio, $\operatorname{los}$ Cursos $1^{\circ}, 2^{\circ}$ y algunas asignaturas de $3^{\circ}$, aclarando así la incógnita que tenían los investigadores de cómo había terminado Daniel la carrera en tan solo tres años. Pero antes, lo primero que hizo al llegar de Madrid y tener claro que deseaba convertirse en médico, fue matricularse en la Escuela de Comercio de Cádiz en «Alemán de $1^{\circ}$ », obteniendo un sobresaliente, asignatura que necesitaba tener aprobada para superar el Curso Preparatorio en la Facultad de Medicina, pues en el Plan de estudios vigente, el del año 1886, se exigía acreditar un curso de Francés (que ya aprobó en el Bachillerato) y otro curso de Alemán.

Fueron varios los sobresalientes obtenidos durante su estancia en la Facultad, pero especialmente hizo méritos para una Matrícula de honor en Patología Quirúrgica II y Patología Quirúrgica III, así como en Ginecología y en «Enfermedades de oído, nariz y garganta», si bien su expediente no se encuentra completo en el Archivo de la UCA. 
Imagen 2 y 3. Caratula del expediente personal de Daniel y solicitud donde refleja los sobresalientes en distintas asignaturas

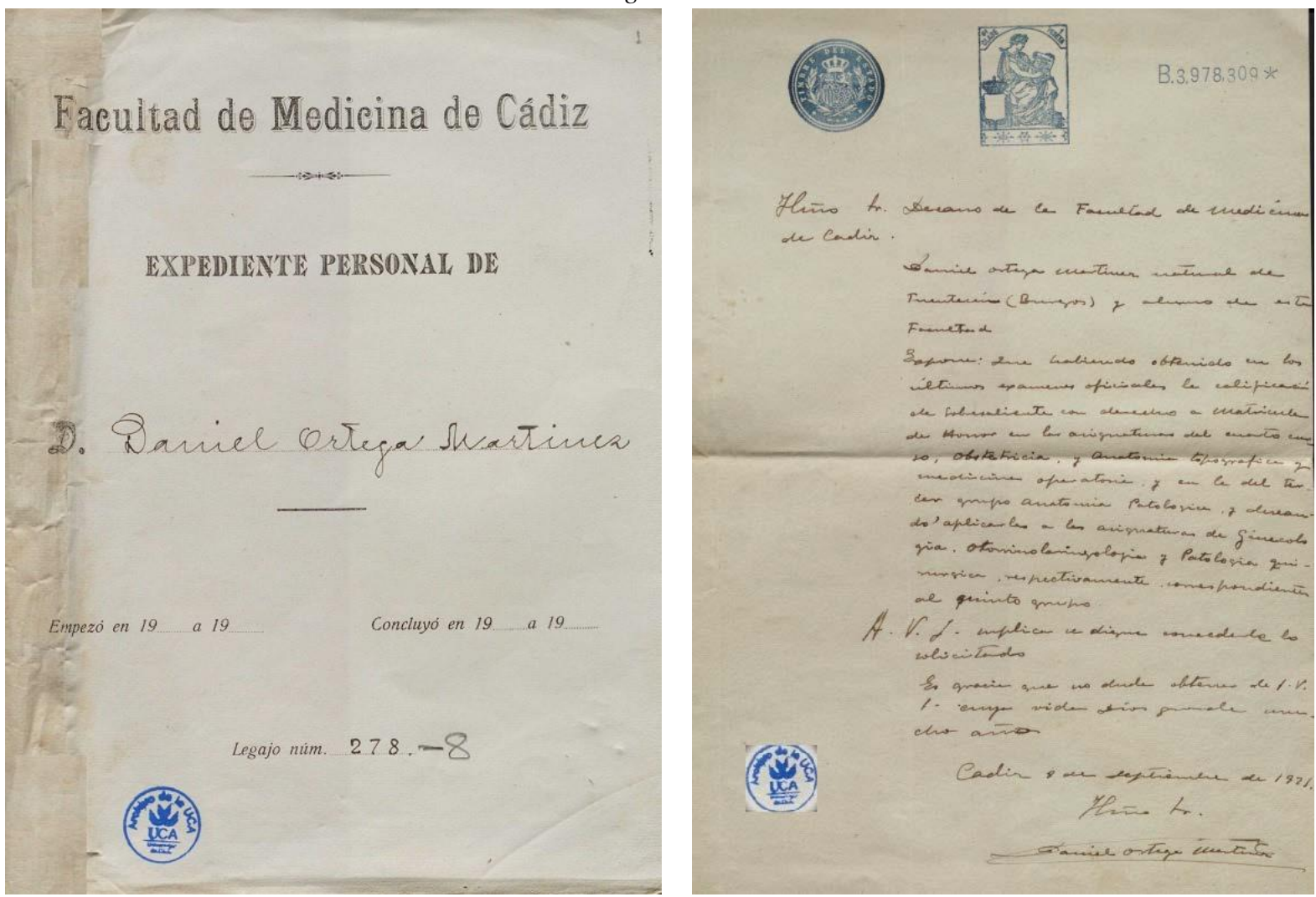

Fuentes: Archivo de la Universidad de Cádiz, Fondo Facultad de Medicina en Cádiz, C-278-8 FC.

Como otros datos de interés diremos que Daniel fue «alumno interno gratuito» en la «clínica de Patología Médica» desde el 1 de junio de 1925, cuando era alumno oficial de $5^{\circ}$ curso de Medicina, y que el 12 de abril de 1926, alegando «asuntos particulares» solicitaba que le dejaran continuar su último año de carrera mediante por «enseñanza libre», renunciando a sus derechos como alumno oficial.

Así es cómo, el día 28 de septiembre de 1926 Daniel pagó las tasas de expedición del título de licenciado en Medicina y Cirugía que había terminado como alumno libre, y se convirtió en el nuevo y brillante médico que se instaló en El Puerto de Santa María.

Hasta aquí todo puede parecer normal y su historia puede ser como la de tantos otros médicos que se licenciaron en Cádiz. Pero a continuación veremos que Daniel Ortega Martínez no era un médico común.

En primer lugar, y como así consta también el Archivo de la Universidad de Cádiz, Daniel Ortega ya era maestro nacional cuando comenzó la carrera de Medicina. Como maestros fueron también sus únicos hermanos Florencio y Vicente.

Daniel había comenzado la carrera de Magisterio en la Escuela Normal de Cádiz en 1914, pero debido al nuevo destino de su padre, trasladó su matrícula a la ciudad de Almería en 1917, y como al año siguiente su padre volvió a pedir traslado al pueblo madrileño de Pinto, fue en la capital de España donde Daniel terminaría su carrera y le darían el título de Maestro 
en febrero de 1919 expedido por la Universidad Central. Una vez obtenido el nombramiento, decidió terminar sus estudios de Bachillerato que iniciara en el Instituto «San Isidoro» de la calle Amor de Dios de Sevilla en 1912, cosa que consiguió en diciembre de 1918.

Imagen 3. Única fotografía de Daniel ortega recién terminada la carrera de medicina paseando por
Barcelona con Luisa Rendón en su luna de miel, Julio de 1928

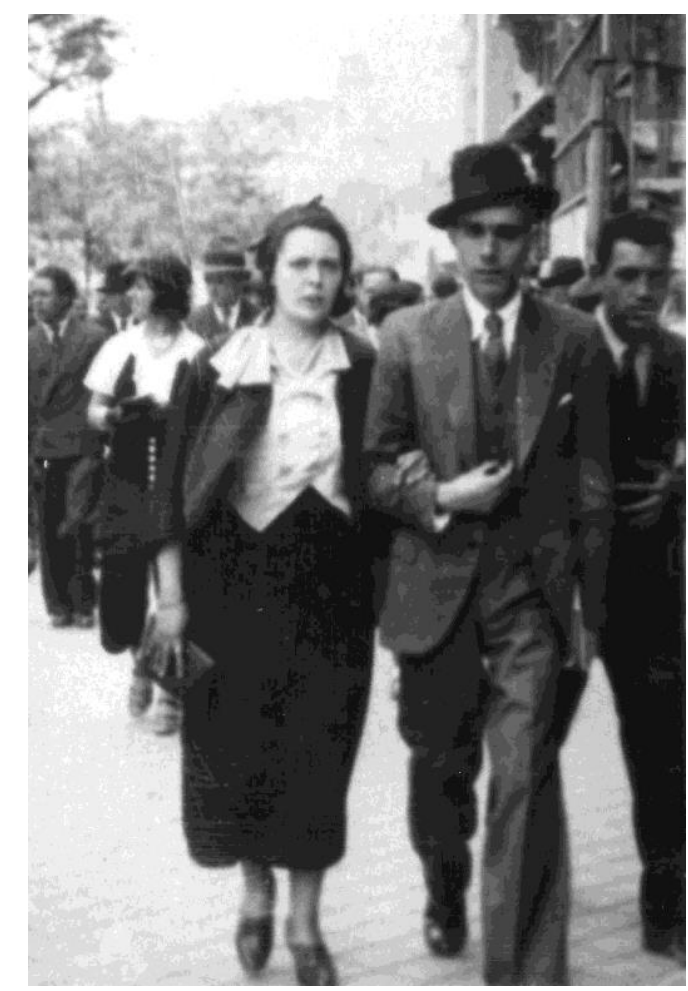

Fuente: Colección familiar de Juan Ortega Rendón

Así que cuando Daniel regresó de Madrid, licenciado del servicio militar en el Regimiento de Ingenieros Telegrafistas, ya tenía en su poder los títulos de Bachillerato y de Magisterio, y podría haber conseguido un puesto de maestro fácilmente si se lo hubiera propuesto, para tener así su futuro asegurado. Pero eso no ocurrió. Como escribiría en una de sus cartas desde la cárcel ${ }^{1}$, comenzó la carrera de Medicina para ayudar a los demás y sentir que era útil a los más necesitados; quería sentirse cerca de los obreros y los trabajadores. Esa era su profunda vocación de la medicina...

Daniel Ortega se afincó en El Puerto en los primeros días de enero de 1927. ¿Por qué allí? No hemos podido saberlo, más allá de algunas conjeturas, pues el hecho de que en esa localidad pasara la temporada estival cuando era pequeño y su familia vivía entonces en Olivares (Sevilla) no creo que influyera mucho. Pero la siguiente información nos irá desvelando detalles que quizás nos ayude a comprender

1 ALMISAS, Daniel Ortega Martínez. Cartas desde la cárcel (1939-1941).

DOI del artículo:

http://dx.doi.org/10.25267/Cuad investig fondos arch UCA.2019.i1.01 
Dos días antes de la aparición de la noticia en El Diario de Cádiz, la noche del 16 de enero de 1927, la policía irrumpió en la tienda de vinos y estanco «La Lucha», en una esquina de la hoy desaparecida plaza de la Pescadería de El Puerto de Santa María. Detuvieron a todos los participantes de una reunión clandestina que discutían en torno a una mesa en un apartado del mismo ${ }^{2}$. Entre los detenidos estaba Daniel Ortega, que según declaró uno de los Guardias civiles había llegado ese mismo día por vez primera a la población, y otros miembros comunistas y sindicales de pueblos cercanos y de la propia ciudad de El Puerto. Todos fueron llevados por la Guardia Civil al mando del teniente Miguel Romero a la Prevención o Arresto Municipal, «para conocer el verdadero fin de la reunión celebrada en la localidad» y dos días después, el 18 de enero, los trasladaron a la Prisión de Cádiz. Antes de su conducción, Daniel Ortega declaraba ante el Juez de Primera Instancia y presentaba una denuncia sobre su detención, por considerarla arbitraria. Algo insólito en aquellos días de la Dictadura de Primo de Rivera en España. ¿Era este Daniel Ortega el mismo «Nuevo Médico» de «brillantes notas» que se publicaba en la prensa?

Claro que sí, pero es que aún no sabían que Daniel Ortega, desde su estancia en Madrid y también durante su servicio militar, perteneció a las Juventudes Socialistas y después formó parte de la escisión de las mismas que formaron el Partido Comunista de España en el otoño de 1921. Ni que desde el II Congreso del PCE celebrado en abril de 1923, Daniel Ortega, con el nombre clandestino de «Carlos Romero», fue elegido como vocal del Comité Nacional (Comité Central) del Partido. Es decir, que el Daniel Ortega que solicitó matricularse en la Facultad de Medicina, el que trabajó en un taller mecánico de coches, especializado en el arreglo de radiadores, para pagarse los estudios y para sentirse parte de los trabajadores manuales, y el que se licenció a finales de 1926 era mucho más que un médico brillante, era un destacado miembro del PCE en plena dictadura de Primo de Rivera.

Por tanto, todo parece indicar que Daniel Ortega estableció su consulta en El Puerto por un motivo meramente partidista, al saber que allí existía una clase trabajadora combativa y organizada en activas Sociedades Obreras, y que le sería fácil conseguir adeptos para el Partido Comunista. A pesar de la represión y de la cárcel, nuestro médico consiguió establecer en muy poco tiempo el primer núcleo comunista en la provincia de Cádiz con la creación de una célula portuense formada por Alfonso Manzanete Flores, trabajador de la Fábrica de Tabacos; Juan Gandulla Vargas, panadero; y Ramón Mila Cristán, obrero metalúrgico. Pero ya antes había realizado un trabajo de proselitismo en Cádiz, mientras estudiaba y trabajaba, organizando a los comunistas gaditanos, como al relojero Francisco Rendón San Francisco, que al cabo de pocos meses se convertiría en su suegro.

La talla política de Daniel Ortega Martínez es incuestionable y en su nombramiento como «Hijo Adoptivo de El Puerto de Santa María» ha influido, por ejemplo, que fuera elegido Diputado a las Cortes representando al Frente Popular de Cádiz en febrero de 1936, pero también se ha subrayado su gran capacidad y generosidad como médico de las clases humildes, siendo coreado en algunos mítines de la provincia como el «médico proletario».

2 ALMISAS, Daniel Ortega Martínez, el médico comunista que revolucionó El Puerto. DOI del artículo: http://dx.doi.org/10.25267/Cuad investig fondos arch UCA.2019.i1.01 
Existen numerosas anécdotas y recuerdos de Daniel Ortega que se han transmitido de generación en generación de portuenses, testimoniando su dedicación desinteresada hacia la gente humilde de El Puerto: Por ejemplo, Francisco Marín comentaba en la web «Gente del Puerto»: «Mi padre un día (soy historiador) me pidió que me enterara qué fue del doctor Daniel Ortega tras la guerra civil. Lo vi cómo sufría cuando le comuniqué que había sido fusilado en Cádiz. Mi padre había llegado al Puerto con su familia, desde El Bosque, por los años en que se estableció ahí el doctor Ortega. Y fue en muchas malas situaciones una ayuda para toda la familia. A mi abuelo Curro lo curó de su enfermedad de estómago y tal era el cariño de mi familia hacia Daniel Ortega que a uno de mis tíos le pusieron su nombre, Daniel. Y yo a mi hijo, por la misma razón, para que el recuerdo del doctor Ortega de alguna manera permanezca, le puse Daniel a mi hijo, Daniel Marín de Ahumada».

Por su parte, Paco Artola recordaba en sus memorias «No soy eterno» ${ }^{3}$ que Daniel Ortega no era el médico de su casa porque él no trabajaba para la Beneficencia, sino que tenía una consulta privada. Y cuenta que «durante una enfermedad de mi hermano, como era imposible localizar al médico, mi padre recurrió a don Daniel. Dado que Ortega era comunista y mi padre socialista, sus ideas eran hasta cierto punto semejantes. Pero pensaría mi padre que al médico le molestarían tantas imágenes de santos en las paredes, de modo que las retiró con premura. Cuando don Daniel entró en la sala y reconoció a mi hermano, inmediatamente recetó medicamentos para la difteria». Y también concuerda esta anécdota que certifica lo comentado por otras personas que conocieron a Daniel, y que es refrendado por el excelente expediente académico ya comentado: «Muchos reconocían la competencia profesional de Ortega. Las familias pudientes de El Puerto traían especialistas de Cádiz... Era costumbre de estos especialistas gaditanos recomendar un médico de esta ciudad y de su entera confianza para seguir la trayectoria del paciente. Y el doctor Ortega era uno de los que más aconsejaban. Los ricos aceptaban a regañadientes a don Daniel. No era para menos: había que recibir en las alcobas más íntimas de sus casas a un comunista ateo». Y terminaba diciendo «Se sabe que cuando el médico salía de casa arrojaban sahumerio y agua bendita para ahuyentar a los duendes sacrílegos que el médico pudiera haber dejado a su paso». Otra anécdota del imaginario popular nos cuenta que una vez acudió de forma urgente y desesperada a una casa de la aristocracia bodeguera de El Puerto y que después de reconocer al paciente, diagnosticarlo y proponer el tratamiento debido, cuando la señora le preguntó que qué se le debía, Daniel contestó que para él no quería nada, y que a cambio ayudara, desde su posición, a que la gente necesitada no pasara hambre repartiendo alimentos entre los pobres. La señora se quedó de piedra...

Muchas anécdotas transmitidas oralmente nos han llegado sobre esta faceta. Y también quiero dejar constancia de que, a pesar de que los derroteros de la política y de su militancia, le llevó a tomar grandes responsabilidades y alejándose de su profesión y de su familia, Daniel fue médico, y médico comprometido, hasta el final de su vida.

Estando preso en la Prisión de San Miguel de los Reyes en Valencia al acabar la guerra, le escribía a sus hijos en Cádiz: «Aquí paso las horas curando enfermos como médico auxiliar

3 ARTOLA, No soy Eterno.

DOI del artículo:

http://dx.doi.org/10.25267/Cuad investig fondos arch UCA.2019.i1.01 
de la prisión. He vuelto a mi antigua profesión, a la que de paso tengo cariño» (26 de mayo de 1939). Y casi hasta el final de sus días, antes de que un pelotón de fusilamiento acabara con su vida en el castillo de San Sebastián (Cádiz), Daniel también hizo las funciones de médico auxiliar de la prisión provincial de Cádiz, y en especial del pabellón de enfermos contagiosos, hecho que originó estas líneas de su esposa Luisa Rendón Martell, presa en la Cárcel de Les Corts (Barcelona), en la última carta que recibió: «Mucho me intranquiliza ese contacto con enfermos contagiosos y te suplico, chachín ${ }^{4}$ querido, que lleves mucho cuidado, pues como tu bien dices, sería estúpido, después de todo lo pasado y de haberte librado de la muerte, habiéndola visto tan de cerca, morir tan oscuramente».

La vida de este médico brillante terminó el 6 de agosto de 1941. En capilla, la noche anterior, escribió a sus hijos que moría «por querer demasiado a España» y «sin tener las manos manchadas de sangre». Los dos ficus del Hospital de Mora, donde estudió y aprendió Daniel las asignaturas clínicas y quirúrgicas, sintieron, bien de mañana, las seis detonaciones del pelotón de ejecución que le trajeron la brisa desde La Caleta.

\section{REFERENCIAS BIBLIOGRÁFICAS}

- Almisas Albéndiz, Manuel. Daniel Ortega Martínez, el médico comunista que revolucionó El Puerto. El Puerto de Santa María: El Boletín, 2016. ISBN: 978-84945532-0-2.

- Almisas Albéndiz, Manuel (Ed.). Daniel Ortega Martínez. Cartas desde la cárcel (19391941). El Puerto de Santa María: El Boletín, 2017. ISBN: 978-84-946248-2-7.

- Artola Beuzón, Francisco. No soy eterno. El Puerto de Santa María: El Boletín, 2011. ISBN: 978-84-938945-4-2.

4 Chachín. Palabra familiar utilizada con frecuencia por Luisa en sus cartas, además de varias derivadas como «chachita» o «chachina». Viene del diminutivo de «muchacho/a». En las Canarias se usa mucho la expresión «chacho». 